\title{
OCIDENTE/ORIENTE:
}

\section{A POÉTICA DE MAX MARTINS E O I CHING}

Yurgel Pantoja Caldas*

RESUMO:

0 presente trabalho busca um exame da obra poética do artista paraense Max Martins, especificamente acerca do livro Para ter onde ir, a partir de sua relação com aspectos da cultura oriental. Tal exame focaliza as relações existentes entre 0 referido livro e o I Ching.

PALAVRAS-CHAVE: tradução, mutação, yin-yang, I Ching.

Desde o início de sua trajetória poética, Max Martins apresenta, em seus textos, ligações com a cultura e o pensamento orientais, a partir de certas noções de doutrinas filosóficas, como o budismo e o tantrismo, com referências a termos em sânscrito e a processos de meditação transcendental. Esses traços orientais, que se revelam numa linguagem sintético-ideogramática, surgem espalhados no decorrer da obra do poeta paraense. Com o livro Para ter onde ir, o poeta apresenta as relações direcionadas para o campo do orientalismo, o qual se configura através do I Ching, também chamado de Livro das mutações. Nesse sentido, é importante verificar as vias percorridas pelo poeta ocidental, latino-americano, brasileiro, amazônico, paraense no trato com os signos milenares do Oriente como instrumento de diálogo e conflito na composição de sua obra.

Quando Max Martins utiliza o I Ching para a composição do seu livro de poemas, existe, por um 1ado, a necessidade de manutenção da primitiva obra chinesa na cadeia de uma tradição literária e, por outro lado, a possibilidade de inserção de Para ter onde ir no cenário mais amplo da literatura, pois a presença desse livro inscreve um movimento de mão dupla: o poeta incorpora ao I Ching uma perspectiva

|*Mestre em Letras: Estudos Literários (Área de concentração: Teoria da Literatura), 2001. 


\section{EMTESE}

Belo Horizonte, v. 6, p. I-253, ago. 2003

ocidental e recupera o jogo enquanto rede simbólica, provocando a formulação de Para ter onde ir.

Nesse trânsito de signos literários e culturais, a referida obra de Max Martins acaba por se inserir em determinada tradição latino-americana onde 0 imaginário ligado às produções poético-narrativas é constituído também a partir das relações que giram em torno das histórias sobre o Oriente. Alguns textos de certos escritores da América Latina expressam uma via de acesso que aponta a direção oriental como fonte de produção literária.

É o caso da ficção de Jorge Luis Borges, de onde se pode extrair um painel através do qual se apresenta uma linguagem particular, que tematiza 0 poderoso manancial de personagens, espaços, crenças, linguagens e pensamentos desenvolvidos a partir de aspectos culturais do Oriente. 0 contato de Borges com a cultura oriental inscreve uma trajetória que se inicia pela leitura das civilizações mediterrâneas, especificamente as do Oriente Médio.

A partir de suas experiências como iniciado na cultura oriental, o autor do Aleph faz-nos ver uma das questões fundamentais para o desenvolvimento de uma linha de força presente em muitos de seus textos: a tradução como leitura complexa, capaz de assumir um estatuto que ultrapassa a simples versão escrita de um texto em língua estrangeira. Nesse sentido, o ato de ler e reler é o mesmo que o de traduzir, o que confere a essa atividade uma nova dimensão: tanto é assim que Borges "assume a autoria da tradução de Rubayat, feita pelo [seu] pai, e que mais tarde the seria atribuída [a ele, o filho], por serem ambos portadores do mesmo prenome" (Souza 1993:102-103).

A obra de Borges apresenta uma visão caleidoscópica do universo e do próprio homem; uma visão que surge como fatal representação de um mundo superior, no conto "0 aleph" (Borges 1997). Tal perspectiva apresenta um mundo em que a órbita do imaginário é traçada em termos análogos aos de uma fissão nuclear, provocada pela movimentação entre as ações de condensação e expansão do tempo e do espaço. No âmbito dessa última categoria, o aleph - signo tomado da cultura judaica que, por sua vez, é um espaço de transição entre o 0cidente e certo Oriente - constitui uma metáfora do mundo e de seus componentes, como o próprio narrador do conto que, ao 
interagir com grandezas físicas distintas (tempo/espaço), fragmenta-se a si mesmo pelo sentido assustador, grandioso e insustentável, através de uma visão completa das coisas do mundo, aliás, de todas as coisas em todos os tempos.

0 aleph funciona como a misteriosa figura que tem o incrível poder de conter todos os seres e que, atuando na completa escuridão - no conto de Borges, 0 aleph encontra-se num porão -, emana sua clara plenitude para um ávido e temeroso narrador que, finalmente, consegue vislumbrar tais maravilhas.

No romance $A$ cidade ausente (Piglia 1993), Ricardo Piglia - outro escritor argentino que segue essa linha que aproxima Oriente e 0cidente - apresenta a máquina de Macedonio, a partir do personagem Stephen Stevensen, o qual encarna a própria criação microscópica do mundo, quando toma parte das narrativas da máquina, tornando-se um personagem duplicado, já que a função da máquina de Macedonio seria a de traduzir várias narrativas a partir do modelo de um conto de Poe, chamado "William Wilson." Isso acontece quando Stevensen torna-se cria de um relato da máquina, no romance, e quando o mesmo personagem posiciona-se como criador de uma ordem para o mundo, no conto "Encontro em Saint-Nazaire". Os mecanismos de atuação e funcionamento da máquina de narrar organizam-se de acordo com os preceitos da Teoria da Repetição, pois em sua série de relatos, "havia uma mensagem implícita que enlaçava as histórias, uma mensagem que se repetia" (Piglia 1993). Para decifrar tal mensagem, teria que ser aplicada, portanto, a lógica da Teoria da Repetição, sem se desprezar, contudo, a investigação de dados alheios ao programa da máquina, visto que ela também incorpora elementos estranhos à sua função de repetidora de relatos. Assim, Stephen Stevensen funciona como investigador da Teoria ao mesmo tempo em que também constitui um objeto da máquina de narrar. Em outras palavras, trata-se de um duplo virtual de William Wilson, cuja história foi a primeira a ser inserida na máquina, quando se esperava que ela pudesse traduzi-la.

0 relato "Os nódulos brancos", um dos tantos que compõem o romance $A$ cidade ausente, trata de uma população cuja linguagem primordial, comum à coletividade, havia sido inscrita nos nódulos brancos - lugar em que se conjugavam os códigos genético e verbal. Era uma linguagem adâmica, dominada por todos, formando um idioma pictográfico, bem próximo do que é apresentado no I Ching, como elemento de controle 


\section{EMTESE}

Belo Horizonte, v. 6, p. I-253, ago. 2003

de situações do porvir, ou como instrumento divinatório, com base na consulta dos trigramas e hexagramas do Livro das mutações.

0 exame das obras de Borges e Piglia aponta para uma situação favorável às formulações literárias baseadas em referências orientais. Trata-se de uma transposição de signos que, no caso de Max Martins, vai redundar numa situação de tradução intersemiótica, de acordo com os critérios apontados por Júlio Plaza. Nesse caso, o poeta paraense pode ser considerado como tradutor do I Ching na medida em que cada poema de Para ter onde ir configura-se como resultado de consulta ao I Ching.

0 texto "A tarefa do tradutor", de Walter Benjamin, além de apresentar uma visão inovadora e desconstrucionista dos modelos estabelecidos de tradução, traça uma espécie de geometria num horizonte de probabilidades presente na relação original-tradução, a partir do momento em que o texto da tradução consegue interferir na construção do sentido do texto original com movimentos decisivos que, por sua vez, modificam a própria estrutura da tradução. De acordo com Benjamin, "assim como a tangente toca o círculo de passagem e num só ponto (...) assim também a tradução toca o original de passagem e no ponto infinitamente pequeno do sentido, para prosseguir (...) a sua própria rota na liberdade do movimento da linguagem" (Benjamin, 1992: 20).

Dessa geometria inaugurada por Benjamin, Haroldo de Campos parece retirar alguns traços para pensar uma quadratura circular, através da tradução de cinco poemas chineses para a língua portuguesa. Seguindo os critérios de tradução sugeridos por Ezra Pound, Haroldo de Campos privilegia a síntese ideogramática da linguagem e do pensamento chineses. A "lógica da analogia", estabelecida a partir de relações conceituais os quais levam em conta uma oposição complementar entre elementos que no Ocidente seriam irreconciliáveis (masculino/feminino), questiona a lógica fundamentada no posicionamento aristotélico e as categorias baseadas no binômio sujeito-predicado, alicerce da linguagem ocidental.

Max Martins estabelece uma linha de tradução para o I Ching, a partir do princípio da transformação dos elementos/signos em constante movimentação: os poemas de Para ter onde ir modificam a interpretação do I Ching, de acordo com a construção dos hexagramas, os quais são constituídos de linhas contínuas e/ou descontínuas. 
0 uso oracular do I Ching obedece a regras de manuseio dos materiais incorporados ao sentido divinatório das linhas dos trigramas e dos hexagramas. A simbologia do I Ching permite uma abordagem capaz de mostrar diversas possibilidades de atuação, no decorrer da análise das informações apresentadas pelo Livro das mutações. Fundamentado na doutrina Yin-yang, o I Ching desenvolve o eterno movimento em busca de um ponto de equilíbrio, através do princípio da mutabilidade, para os fenômenos do mundo.

Enquanto representação de elementos contrários, que não se permitem entrar em oposição absoluta, yin e yang pré-figuram, respectivamente, os traços quebrados e inteiros das linhas do I Ching, o qual se organiza a partir de uma estrutura em que atuam três elementos fundamentais: Céu, Homem e Terra; tais elementos desdobram-se em várias séries de tríades sob o efeito da mutabilidade condição que confere a dinâmica da movimentação às séries de oposição. Somente a partir da compreensão de tal condição podem-se criar os mecanismos de domínio dos vários processos de transformação que aparecem no I Ching.

No processo de identificação dos poemas de Para ter onde ir com os hexagramas do I Ching, encontramos a alternativa de relacionar o mesmo poema a mais de um hexagrama, da mesma forma que um só hexagrama pode fazer referências a textos diferentes de Max Martins. 0 primeiro poema, "Ir", serve como epígrafe para o livro:

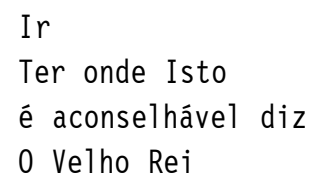

Do corpo do texto, pode-se extrair uma frase, que é uma orientação freqüente no I Ching: "é aconselhável/Ter onde/Ir." A insistência da frase, que aparece em vários hexagramas, indica a necessidade de repetição dessa orientação aos consulentes e marca a condição básica da mudança através do contexto próprio de cada hexagrama em que a referida expressão surge.

As referências plásticas de Max Martins, uma frente alternativa aberta no sentido de compreender a poética do artista, servem para marcar a importância de determinados pintores paraenses para a formulação de sua poética, além de mostrarem 


\section{EM TESE}

Belo Horizonte, v. 6, p. I-253, ago. 2003

uma via específica da construção visual indicada pela elaboração da colagem, levada a cabo pelo poeta. Esse processo de criação, que incorpora elementos plásticos a uma poética visual, permite uma análise dos textos de Max Martins que leve em consideração aspectos ligados à fotografia e ao cinema, através da via da montagem. Dessa forma, o aspecto visual do I Ching se presta a uma análise marcada pelo caráter ideogramático da linguagem chinesa, cujos elementos são manipulados esteticamente pelo poeta Max Martins.

ABSTRACT :

This paper aims at an examination of the poetical works of Max Martins - an artist from the state of Pará focusing particularly on Para ter onde ir, in order to discuss its relation with aspects of oriental culture, especially I Ching.

KEY WORDS: translation, change, yin-yang, I Ching.

REFERÊNCIAS BIBLIOGRÁFICAS

BENJAMIN, Walter. A tarefa do tradutor. Trad. Karlheinz Burck et al. Rio de Janeiro: Universidade Federal do Rio de Janeiro, 1992.

BLOFELD, John. I Ching; o livro das transmutações. Trad. Ronald Sérgio de Biasi. Rio de Janeiro: Record, 1968.

BORGES, Jorge Luis. O Aleph. Trad. Flávio José Cardoso. Porto Alegre: Globo, 1997.

- O fazedor. Trad. Rolando Roque da Silva. Rio de Janeiro: Bertrand Brasil, 1995.

- Sete noites. Trad. José Silvério Trevisan. São Paulo: Max Limonad, 1987.

CAMPOS, Augusto de; CAMPOS, Haroldo de; PIGNATARI, Décio. Mallarmé. São Paulo: Perspectiva, 1991.

CAMPOS, Haroldo de. A arte no horizonte do provável. São Paulo: Perspectiva, 1997.

- (Org.). Ideograma: poesia, lógica, linguagem. São Paulo: Edusp, 1994.

CHAN, Tung-Sun. Filosofia del Oriente. Trad. Javier Troncoso. México: Fondo de Cultura Económica, 1954.

GRANET, Marcel. O pensamento chinês. Trad. Vera Ribeiro. Rio de Janeiro: Contraponto, 1997. 
HUIZINGA, Johan. Homo ludens. Trad. João Paulo Monteiro. São Paulo: Perspectiva, 1999.

JULIEN, François. Figuras da imanência; para uma leitura filosófica do I Ching, o clássico da mutação. Trad. Carlos Alberto da Fonseca. São Paulo: Ed. 34, 1997.

- Tratado da eficácia. Trad. Paulo Neves. São Paulo: Ed. 34, 1998.

MARTINS, Max. Não para consolar. Belém: CEJUP, 1992.

. 0 poeta e seu diário. Revista Unamazônia. Belém, v. 1, n. 0, junho de 1998. p. 34-41.

- Para ter onde ir. São Paulo: Massao Ohno, 1992.

Monega1, Emir Rodriguez. Borges: uma poética da leitura. Trad. Irlemar Chiampi. São Paulo: Perspectiva, 1980.

Paz, 0ctavio. Conjunções e disjunções. Trad. Lúcia Wisnik. São Paulo: Perspectiva, 1979.

- Signos em rotação. Trad. Sebastião Uchoa Leite. São Paulo: Perspectiva, 1996.

PEREIRA, Maria Antonieta. A rede textual de Ricardo Piglia. São Paulo: Fundação Memorial da América Latina, 1999.

- Museu-máquina; Ricardo Piglia e seus precursores. Belo Horizonte: Faculdade de Letras da UFMG, 1997 (Tese, Doutoramento em Literatura Comparada).

- e Santos, Luís Alberto Brandão. Palavras ao Sul; seis escritores latino-americanos contemporâneos. Belo Horizonte: Autêntica/FALE, 1999.

PIGLIA, Ricardo. A cidade ausente. Trad. Sérgio Molina. São Paulo: Iluminuras, 1993.

- Prisão perpétua. Trad. Sérgio Molina, Rúbia Prates Goldoni. São Paulo: Iluminuras, 1989.

PLAZA, Júlio. Tradução intersemiótica. São Paulo: Perspectiva, 1987.

POUND, Ezra. Os cantos. Trad. José Lino Grünewald. Rio de Janeiro: Nova Fronteira, 1986.

SOUZA, Eneida Maria de. Traço crítico. Belo Horizonte: Editora UFMG/Rio de Janeiro: Editora UFRJ, 1993.

SOUZA, Eneida Maria de; FONSECA, Maria Nazareth. Ensaios de semiótica: cadernos de Lingüística e Teoria da Literatura. Belo Horizonte: Departamento de Lingüística e Teoria da Literatura, FALE/UFMG, n. 1, dez. 1986.

WILHELM, Ricard. I Ching; o livro das mutações. Trad. Alayde Mutzenbecher. São Paulo: Pensamento, 1999. 